\title{
A autoridade do professor na sociedade escolarizada
}

\author{
Elizabeth Tunes, (D) I, Zoia Prestes (D) II \\ ${ }^{I}$ Universidade de Brasília e Centro Universitário de Brasília, Brasília, DF, Brasil

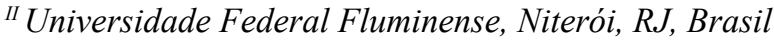

\begin{abstract}
Resumo
O presente artigo tem como finalidade examinar como a consolidação da mentalidade escolarizada articula-se ao fracasso da escola. Parte-se de uma breve caracterização do momento histórico de nascimento da escola, há aproximadamente oitocentos anos, até chegar-se à era da industrialização, há cerca de duzentos anos, quando começa a desenvolver-se o que se denomina, na literatura, de mentalidade escolarizada. Após caracterizar, brevemente, essa mentalidade, são apresentados argumentos visando demonstrar de que modo isso contribuiu para o fracasso da escola, minando a autoridade do professor e gerando a possibilidade de emergência da escola militarizada. Conclui-se que a perseverança no mito da escolarização por meio da difusão da ideia de que a crise da educação é de caráter técnico conduz a iniciativas de intensificação de formas de avaliação do processo de ensino-aprendizagem e à militarização das escolas como forma de conter a violência. O mito da escolarização é um aliado importante do ideal de controle social da aprendizagem.
\end{abstract}

Palavras-chave: educação; autoridade; escolarização.

\section{Teacher authority in schooling society}

\begin{abstract}
In this article we aim to examine how schooling, a kind of mental space, is related to the failure of school. We begin presenting a brief characterization of the historical moment of school's birth about eight hundred years ago. Then we move to the industrialization era which began approximately two hundred years ago and in which was born a kind of mentality called schooling. After a brief characterization of schooling mentality, we present arguments in order to demonstrate how it contributed to school failure by collapsing teacher's authority. The death of teacher's authority, in its turn, creates the possibility of emergence of militarized school. It is concluded that perseverance in the myth of schooling, carried out by spreading the idea that the education crisis is of a technical nature, leads to initiatives to intensify forms of evaluation of the teaching-learning process and the militarization of schools as a way to contain violence. The myth of schooling is an important ally of the ideal of social control of learning.
\end{abstract}

Keywords: education; authority; schooling.

\section{Introdução}

Para que o cidadão possa ser persuadido de que é ele quem controla o seu próprio destino, de que a moral é que preside as decisões, de que a tecnologia é uma força a seu serviço e não uma força avassaladora, tornou-se hoje imprescindivel deformar a informação. O ideal de informar o público foi substituído pela tentativa de convencer esse público de que as ações a ele impostas são, na realidade, ações desejadas.

Ivan Illich (1975, p. 14-15)

São difíceis os tempos hoje vividos, especialmente no campo da Educação. A reportagem apresentada a seguir ilustra, sem qualquer dúvida, a natureza do mal que nos atinge. Ela foi publicada pelo $O$ Globo, no dia 1/10/2019, e assinada por Bruno Alfano (2019). Segundo a notícia, um deputado estadual do PSL, no Rio de Janeiro, Alexandre Knoploch, protocolou projeto de lei instaurando a obrigatoriedade para docentes da rede pública e privada se submeterem a exame toxicológico "específico para substâncias psicoativas ilícitas que causem dependência ou, comprovadamente, comprometam a capacidade intelectual e de raciocínio". A Secretaria de Estado de Educação concentraria o resultado dos exames, publicando-os em seu sítio eletrônico oficial, prevendo-se que "os do-

^Endereço para correspondência: Universidade de Brasília. Campus Asa Norte - ASA NORTE CEP: 70000-000 - Brasília, DF - Brasil. E-mails: bethtunes( gmail.com,zoiaprestes@yahoo.com.br.

Os dados completos das autoras encontram-se ao final do artigo. centes cujo os (sic) exames apontarem o uso de entorpecentes e substâncias psicoativas ficarão impedidos de lecionar até a realização de próximo exame que ateste a ausência destas mesmas substâncias". Seus salários seriam descontados e, se reincidentes acima de um teto, seriam, então, exonerados.

De acordo com o repórter, houve alguma reação ao projeto. Opositores afirmaram sua inconstitucionalidade. Outros enxergaram nisso uma lógica moralista de associar o docente ao drogado, desmoralizando os profissionais da educação. Ainda outros, naturalizando o episódio, argumentaram que o referido projeto não deverá ser aprovado, que seu autor estaria apenas buscando obter alguma notoriedade.

De todo modo, seja lá o que vier a acontecer com a inusitada proposta, o fato que nos parece importante realçar é que a ideia foi apresentada e justificada, a ideia está posta, ela existe. Isso é por si só muito assustador. Não bastassem apenas as iniciativas para se tentar exercer controle absoluto sobre o pensamento e as ações dos docentes tal como a proposta veiculada pelo programa Escola sem Partido, surge agora a assombrosa intenção de se fazer também o controle de seus corpos. É a própria existência da ideia o acontecimento aviltante. Por que se deseja com tamanha avidez o controle das mentes e dos corpos dos professores? O que motiva ou de onde surge esse desejo aparentemente intempestivo? É tendência nova que está a emergir? 
Que intenção esse desiderato encobre? No presente ensaio, temos como objetivo destacar pontos que merecem reflexão a respeito dessas questões apresentadas.

\section{O surgimento da instituição escolar e a escolarização da sociedade}

[...] nos paises com deficiencia de escolas, onde o rádio de pilha já chegou a todas as aldeias, jamais deveríamos subestimar a função educacional dos grandes dissidentes carismáticos, como Dom Hélder Câmara, no Brasil, e Camilo Torres, na Colômbia. Castro qualificava seus primeiros discursos carismáticos de "sessões pedagógicas. O espirito escolarizado vê nesses processos apenas a doutrinação politica, passando-lhe despercebido o seu objetivo educacional.

Ivan Illich (1975, p. 97)

A escola que conhecemos hoje é instituição de muita idade - tem cerca de oitocentos anos. Ela surgiu com a descoberta da tecnologia do alfabeto, a partir do século XII, criando a possibilidade da emergência do texto livresco, que, por sua vez, legitimou a perpetuação das instituições escolásticas ocidentais. Viveu-se, naquele momento histórico de transição da era da leitura monástica para a era da leitura escolástica, uma verdadeira revolução cultural, e, como diz Illich (2002, p. 7), a "cultura livresca universal converteu-se em núcleo da religião secular do Ocidente e a escolarização, em sua Igreja". O autor descreve com maestria e profundidade a transformação no modo de leitura, na passagem da era monástica para a escolástica, destacando um breve momento, ainda que muito importante, da história do alfabeto. A página do livro, que até então "era uma partitura para beatos bisbilhantes, transformou-se, de repente, em um texto organizado oticamente para pensadores lógicos" (ILLICH, 2002, p. 8). Foi com essa organização e estrutura que o texto livresco constituiu-se na "metáfora raiz" de uma época.

Daquele momento em diante, as instituições educativas secularizaram-se e multiplicaram-se. Contudo, ao longo do tempo, desenraizaram-se cada vez mais do texto livresco, dando início, há aproximadamente duzentos anos, ao que Illich (1975) chama de "era da escolarização". Hoje, é possível afirmar que o livro texto foi praticamente substituído pela tela, pelos meios de difusão de informação, pelas imagens técnicas. Curiosamente, a escolarização ou mentalidade escolarizada parece estar ainda mais fortemente presente na vida social do que esteve anteriormente. A mentalidade escolarizada, em sua essência, é a que confunde "processo com substância" (ver ILLICH, 1979), admitindo-se, por exemplo, que, quanto mais longo o tempo de frequência à escola, melhores serão os resultados de aprendizagem; que obtenção de diploma ou título universitário é sinônimo de obtenção de competência; que a quantidade de artigos científicos publicados por um professor universitário atesta sua capacidade de dizer algo novo; que cuidar da saúde é o mesmo que fazer tratamento médico; que segurança pública é o mesmo que proteção policial; e segurança nacional, a existência de aparato militar.
Muitos acreditaram, e talvez ainda acreditem, que Ivan Illich propugnava que a escola fosse abolida da sociedade. ${ }^{1}$ Ele atribuiu essa interpretação equivocada ao título escolhido pelo editor de seu livro (De-schooling Society), que traía o seu pensamento. O que auspiciava na obra era, na verdade, a desinstitucionalização da escola, ideia que, mais tarde, ele próprio criticou por entender que "a alternativa à escolarização não devia consistir em um tipo diferente de instituição educativa, ou em um projeto que inserisse a instrução em todos os aspectos da existência, mas em uma sociedade que promovesse uma atitude diferente das pessoas em relação aos instrumentos" (ILLICH, 1990, p. 15, grifos nossos).

Em síntese, em 1990 Illich mantinha a crítica à ideologia da escolarização ou à mentalidade escolarizada, ou seja, era contumaz. Em 1968 já a tecia, analisando especialmente o seu significado nos Estados Unidos e nos países da América Latina, aos quais se impunham os modelos estadunidenses, especialmente por meio do programa Aliança para o Progresso. Alguns desses textos foram reunidos em coletânea, publicada pela primeira vez em 1969. Na obra, indica ser seu objetivo "questionar a natureza de algo supostamente certo" (ILLICH, 1975, p. 9), criticar as instituições, pois estas "criam certezas e, se tomadas a sério, as certezas entorpecem os ânimos e algemam a imaginação" (ILLICH, 1975, p. 9). Por isso, diz com ironia, no prefácio: "Cada um deles serviu para irritar um burocrata bem instalado, no momento em que este encontrava dificuldade em racionalizar uma posição consagrada" (ILLICH, 1975, p. 9).

O processo de escolarização produz muitas certezas. Uma delas, por exemplo, é a de que a frequência à escola é indispensável para que um indivíduo se torne útil à sociedade, e tanto mais útil será quanto mais tempo frequentar a escola. Essa é uma certeza que não se ancora nos fatos, portanto não passa de ideologia. Se observarmos o nosso entorno imediato, veremos que a grande maioria das pessoas que presta serviço das mais variadas naturezas (domésticos, comerciais, de construção, limpeza e manutenção de espaços públicos), portanto pessoas que, indubitavelmente, seriam chamadas de úteis à sociedade, não são as que usufruíram de maior tempo de frequência à escola. Outra certeza é a de que educação, necessariamente, implica anos de frequência à escola $\mathrm{e}$ a de que uma sociedade será tão mais civilizada quanto maior for o número de cidadãos que frequentaram ou frequentam as carteiras de uma sala de aula. Esquecem-se do ensinamento de Paulo Freire (1979, p. 35):

Uma educação que procura desenvolver a tomada de consciência e a atitude crítica, graças à qual o homem escolhe e decide, liberta-o em lugar de submetê-lo, de domesticá-lo, adaptá-lo, como faz com muita frequência a educação em vigor num grande número de países do mundo, educação que tende a ajustar o indivíduo à sociedade, em lugar de promovê-lo em sua própria linha.

${ }^{1}$ Essa crença tornou-se ainda mais forte no Brasil devido à tradução ainda mais inadequada do título da obra em português: Sociedade sem escolas (ILLICH, 1979).

Fractal, Rev. Psicol., v. 32 - n. esp., p. 185-189, 2020 
A ideologia a que nos referimos propugna que é pela Educação - vale destacar, escolar - que uma nação resolve, se não todos, pelo menos os seus mais importantes problemas. Essa é a ideologia da educação como panaceia universal que, como bem sabemos, não resiste minimamente ao exame histórico. Essas e muitas outras certezas que são afirmadas em relação à escola e suas relações com a educação não passam de quimeras, de fantasias que encobrem a realidade dos fatos e são propagadas como dogmas da escola, a igreja oficial dos tempos seculares, tal como a denomina Illich (1975, p. 102-103), para quem o impulso para a escolarização universal, surgido há dois séculos, sempre teve como objetivo:

[...] incorporar todos os indivíduos ao Estado industrial. $\mathrm{Na}$ metrópole industrial, a escola foi a instituição integradora. Nas colônias, ela inculcou nas classes dominantes os valores do poder imperial e confirmou nas massas o sentimento de inferioridade diante dessa elite escolarizada. Tanto a nação como a indústria da era pré-cibernética seriam inconcebíveis sem o batismo universal conferido pela escola. Nesta era, o indivíduo que não completa os seus estudos corresponde ao marrano relapso da Espanha, no século XI.

\section{O ocaso da autoridade}

Vê-se, pois, que a ideia de escolarização universal tem sentido bem estabelecido: a instilação de valores para a domesticação de corpos e mentes. Para isso, contudo, seria necessário instituir, por meio das práticas escolares, o controle social da aprendizagem, isto é, o controle sobre o que seria aprendido, acontecimento tornado possível por constrangimentos e imposições feitas ao ato de ensinar, portanto, aos professores. Programas curriculares, métodos e técnicas de ensinar, formas de avaliação, adoção e formatação de livros didáticos e ações congêneres foram desenvolvidos com requinte e detalhe, gerando uma tal padronização e uniformização do ensino que, nos dias de hoje, chega-se a sugerir a professores o tom de voz e o modo de falar que deve adotar para dirigir-se a seus alunos. Em síntese, visa-se à criação do autômato professor para garantir a criação de autômatos alunos. Vê-se, assim, que a realização do controle social da aprendizagem por meio do controle da ação docente fere, necessariamente, a autonomia do professor, enfraquecendo até à destruição a autoridade do professor.

Desde o início da era escolástica o mestre usufruía de autoridade diante dos estudantes. Anteriormente, no período monástico, a autoridade era conferida aos textos sagrados que narravam a história da criação do mundo. A própria estrutura do texto atesta esse fato. Eles iniciavam-se sem título, com uma frase inicial - incipit - que dava o tom da narrativa. O incipit era um auctoritas, isto é, algo que vale a pena ser repetido, conservado (ver ILLICH, 2002). Por exemplo, no século XII, no livro de Hugo de São Vítor (2001, p. 47), que marca a transição da era monástica para a escolástica, o incipit - "De todas as coisas a serem buscadas, a primeira é a Sapiência, na qual reside a forma do bem perfeito" - inseria a obra numa tradição didascálica, isto é, dos assuntos relativos à instrução. Essa tradição remontava à Varron, que foi bibliotecário de César e Augusto e autor da primeira gramática normativa do latim. O tempo de Hugo foi o século XII, o século berço da revolução cultural que trouxe a transformação na estrutura do texto, nas formas de leitura, e gestou a ideia de autor. Surgia o período escolástico, que deu lugar à secularização do ensino e da aprendizagem. Nos breves momentos da era que se iniciava, a autoridade transferiu-se do texto para o autor, que, muitas vezes, eram os próprios mestres.

As palavras autor e autoridade são de origem latina. Derivam-se do verbo augere, que significa fazer crescer. Diz respeito à atividade de jogar sementes para que cresçam. Têm origem no mito da fundação de Roma por Rômulo, que "plantou a raiz sobre a qual a cidade assenta, e da qual sorve a seiva que faz com que cresça e se torne o império do mundo"; para que possa vingar, é necessário que a cidade permaneça sempre ligada ao seu autor (FLUSSER, 2008, p. 102). A ligação cidade-fundador seria permanentemente feita pelas autoridades, o núcleo da república romana. Tal ligação era realizada pelos construtores de pontes - pontífices -, cuja função era religiosa, e pelos administradores, como os denomina Flusser, que propulsionariam (tradire) a seiva, a mensagem do autor, em direção ao futuro civilizatório. O primeiro tipo de autoridade era o maior (magister), e o segundo, o menor (minister). A noção de autoridade liga-se, pois, à religião e tradição. A autoridade requer, sem dúvida, assento no passado.

Contudo, para Arendt (2005) e também para Flusser (2008), a autoridade desapareceu do mundo moderno, dado que "não mais podemos recorrer a experiências autênticas e incontestes comuns a todos" (ARENDT, 2005, p. 127). Para ela, a morte da autoridade é fase final, decisiva de um processo de enfraquecimento contínuo, por séculos, da religião e da tradição. O enfraquecimento da tradição não equivale, conforme entende, à perda do passado, pois que diz respeito ao fio que guia os seres humanos com segurança pelos vastos domínios do passado. Significa, entretanto, que a dimensão do passado encontra-se em risco. Ou seja, o esquecimento ronda-nos, ameaçando-nos da privação da "dimensão de profundidade na existência humana” (ARENDT, 2005, p. 131), uma vez que esta não pode ser alcançada a não ser pela recordação. Algo similar aconteceu à religião, na medida em que a fé foi posta em dúvida e ameaçada pela crise da religião institucional.

A ideia de autoridade deve ser distinguida de poder, violência e persuasão. Por requerer obediência, autoridade é, muitas vezes, equivocadamente confundida com autoritarismo, que implica alguma forma de violência ou coerção pela força. Ela é reconhecida, mas não imposta pela força. Na verdade, quando "a força é usada, a autoridade em si mesma fracassou" (ARENDT, 2005, p. 129). Deve também ser diferenciada da persuasão por argumentos que pressupõem simetria entre os envolvidos e opera mediante um processo de argumentação. A noção de autoridade implica, pois, assimetria nas relações e, portanto, a ideia de hierarquia. 
A assimetria é própria da relação mestre-discípulo, por exemplo, na qual o discípulo submete sua vontade ao mestre, mas não sua inteligência, conforme bem examina Rancière (2004). Voluntariamente, o estudante deixa-se guiar pelo mestre sem, contudo, abrir mão de seu próprio poder de pensar. Essa é a pedagogia da emancipação que se opõe à do embrutecimento. Nesta, a inteligência do aluno submete-se à do mestre; naquela, a inteligência do aluno "não obedece senão a ela mesma, ainda que a [sua] vontade obedeça a uma outra vontade", a do mestre (RANCIÉRE, 2004, p. 32). É, portanto, no âmbito da vontade que a assimetria se configura, e não no da inteligência.

Contudo, a escola que se forjou há aproximadamente duzentos anos não é a que adota a pedagogia da emancipação. O exame crítico do método de Jacotot feito por Rancière, para apresentar apenas um exemplo, demonstra isso. Ao final do século XVIII, Jacotot já tecia críticas à mentalidade escolarizada por entendê-la como a infantilização generalizada dos indivíduos (RANCIÈRE, 2004). Ao final das contas, essa infantilização está embutida na mentalidade escolarizada que serve ao controle social da aprendizagem dos alunos, exercendo-se o controle das atividades do professor, que, assim, também é tratado de modo infantilizado. Então, impõe-se à relação professor-aluno uma assimetria, não da vontade, mas da inteligência, e ao mesmo tempo solapa-se a possibilidade de exercício da inteligência do professor, ditando-lhe desde métodos de ensino até formas de se comportar diante dos alunos.

No mundo atual, a educação passa por uma crise que, embora possa manifestar-se com peculiaridades em cada país, é geral, e seu caráter é fundamentalmente político. Trata-se da crise de autoridade que, de maneira global, atinge as sociedades dos tempos modernos. Costuma-se acreditar que a crise da educação diz respeito, em sua essência, a aspectos técnicos ligados ao insucesso da instituição escolar para promover a aprendizagem dos estudantes, isto é, que ela resume-se ao fato de "Joãozinho não aprender a ler", expressão empregada por Arendt (2005, p. 222). Contudo, dada a sua envergadura, essa crise é, sem dúvida, de caráter eminentemente político.

\section{A militarização da escola}

Nunca se deve colocar armas nas mãos do povo. Todo aquele que põe armas nas mãos do povo faz obra de destruição. As armas colocadas nas mãos do povo serão sempre usadas contra o próprio povo. As armas aniquilam o pobre que as recebe. Somente a pedra e o pau que o homem apanha em sua cólera serão capazes de não desonrá-lo como homem.

Francisco Julião (ILLICH, 1975, p. 23)

$\mathrm{O}$ ato de educar implica, necessariamente, o exercício da autoridade, tal como esta é referida no mito da fundação de Roma. É forçosamente necessária a ligação entre o mundo velho no qual aportam as crianças e o novo que está por vir e de cuja construção elas irão participar. É preciso propulsionar a seiva em direção ao novo mundo que surgirá. O mestre possibilita essa propulsão e, desse modo, o ato de educar ancora-se no pas- sado e projeta-se no futuro num constante movimento de renovação. Portanto, o mestre é autoridade, e somente como tal lhe é possível realizar o ato educativo.

A ideia que se desenvolveu com força na era industrial de que é possível o controle social da aprendizagem por meio do controle das ações de quem ensina, entretanto, conforme já se apontou, estraçalhou a autoridade do professor, inviabilizando a possibilidade do acontecimento da verdadeira ação educativa. Privado de sua autoridade, o professor viu-se diante de crianças e jovens deixados a si mesmos, isto é, nesta circunstância, emancipados da autoridade do adulto. Jogados a si mesmos, acabam por entregar-se à tirania do próprio grupo e sua reação "tende a ser ou o conformismo ou a delinquência juvenil, e frequentemente é uma mistura de ambos" (ARENDT, 2005, p. 231). Eis, então, que recrudesce o fenômeno da violência escolar que, nas duas últimas décadas, tem levado estudiosos a buscarem por suas causas e por modos de atenuá-la (ver RISTUM, 2001, 2010).

Entretanto, tenciona-se, por todos os meios, preservar o mito da escolarização, propagando-se a ilusão de que a crise da educação é de caráter técnico, bastando encontrar meios de combater a ineficiência da escola para produzir bons resultados de aprendizagem dos alunos e a violência que brota no interior das escolas. No âmbito das tentativas de melhorar a aprendizagem dos estudantes, multiplicam-se, indefinidamente, as formas de avaliação que não resultam, contudo, em quaisquer políticas de reestruturação, reformulação e transformação da estrutura da instituição escolar, mas apenas reverberam no fortalecimento do ideal social meritocrático do "salvem-se os melhores", sejam alunos ou instituições. No que tange à violência escolar, o Estado reivindica, no momento atual, a implantação da militarização das escolas, projeto já iniciado em algumas cidades do país. Em Brasília, a capital federal, esse projeto recebeu o ardiloso nome de Escola de Gestão Compartilhada, que, conforme o artigo $1^{\circ}$, visa à "colaboração entre a Secretaria de Estado de Educação e a Secretaria de Estado de Segurança Pública, por intermédio de ações conjuntas a fim de proporcionar uma educação de qualidade, bem como construir estratégias voltadas ao policiamento comunitário e ao enfrentamento da violência no ambiente escolar, para a promoção de uma cultura de paz e o pleno exercício da cidadania" (SECRETARIA DE ESTADO DE EDUCAÇÃO DO DISTRITO FEDERAL, 2019, p. 3). Uma rápida inspeção no organograma da Escola proposta permite verificar que não há entre as duas gestões qualquer coordenação de ações, de tal sorte que a palavra compartilhada é empregada no sentido de dividir, separar, compartimentar, e não no seu sentido mais usual no campo da educação, o de arcar, juntamente. Retoma-se aqui a frase final da epígrafe inicial: "O ideal de informar o público foi substituído pela tentativa de convencer esse público de que as ações a ele impostas são, na realidade, ações desejadas" (ILLICH, 1975, p. 14-15).

Encerramos com o mesmo autor, que em 1968, em tom profético, afirmava: 
Finalmente, o culto da escolarização levará à violência, tal como sempre aconteceu com a implantação de "qualquer" religião. Se for permitida a difusão do evangelho da escolarização na América Latina, os contingentes militares destinados a reprimir a rebelião terão que de ser aumentados. Somente a força poderá controlar a insurreição insuflada pelas expectativas frustradas, criadas pela propagação do mito da escola. A manutenção do atual sistema escolar pode vir a constituir um importante degrau no caminho do fascismo, na América Latina. Somente o fanatismo inspirado pela idolatria de um sistema pode chegar a racionalizar a maciça discriminação que resultará fatalmente de mais vinte anos transcorridos a classificar, por meio de notas escolares, uma sociedade carente de capitais (ILLICH, 1975, p. 97).

\section{Informações sobre as autoras:}

\section{ElizabethTunes}

(iD) https://orcid.org/0000-0002-6884-8521

(9) http://lattes.cnpq.br/0384208157289616

Possui graduação em Psicologia pela Universidade de Brasília, mestrado e doutorado em Psicologia pela Universidade de São Paulo. Atualmente, é pesquisador associado da Universidade de Brasília e professora do Centro Universitário de Brasília. Sua atividade de pesquisa focaliza, principalmente, os seguintes temas: conhecimento científico e conhecimento escolar, relação professoraluno, aprendizagem e desenvolvimento, desenvolvimento psicológico atípico e deficiência mental, processos de escolarização e o significado social da escola.

\section{Zoia Prestes}

(iD) https://orcid.org/0000-0002-1347-3195

\section{(9) http://lattes.cnpq.br/1927800358488148}

Sou a Professora Zoia Prestes. Estou e sempre estarei ao lado daqueles que lutam pela justiça social no Brasil e no mundo. Sou admiradora de Paulo Freire, Darcy Ribeiro e Anísio Teixeira, além de Lev Vigotski, é claro. Admiro a arte, gosto, em especial, de música e de cantar, principalmente a música internacional. Sou filha de Luiz Carlos Prestes e de Maria Prestes. Durante a ditadura militar que se instalou no Brasil a partir de 1964, vivi exilada com meus pais na União Soviética, e foi lá, em Moscou, que me graduei e me tornei Mestre em Pedagogia e Psicologia Pré-Escolar pela Universidade Estatal de Pedagogia de Moscou. Tornei-me Doutora em Educação pela Universidade de Brasília, orientada pela Professora Elizabeth Tunes, que hoje é uma grande amiga. Trabalho como professora na Faculdade de Educação da Universidade Federal Fluminense e como professora colaboradora no curso de Pós-graduação em Psicologia do Centro Universitário de Brasília. Empreendo esforços para desenvolver pesquisas na área de Educação, Psicologia e Desenvolvimento da Criança com base na teoria histórico-cultural. Traduzo do russo para o português e já publiquei no Brasil alguns livros e textos que são o resultado desse trabalho.

\section{Contribuições das autoras:}

As autoras colaboraram ao longo do processo, desde a elaboração até a revisão final do manuscrito. Ambas aprovaram o manuscrito final para publicação.

\section{Como citar este artigo:}

\section{ABNT}

TUNES, Elizabeth; PRESTES, Zoia. A autoridade do professor na sociedade escolarizada. Fractal: Revista de Psicologia, Niterói, v. 32, n. esp., p. 185-189, jun. 2020. https://doi.org/10.22409/19840292/v32_i-esp/38850

Fractal, Rev. Psicol., v. 32 - n. esp., p. 185-189, 2020

\section{APA}

Tunes, E., \& Prestes, Z. (2020, Junho). A autoridade do professor na sociedade escolarizada. Fractal: Revista de Psicologia, 32(esp.), 185-189. doi: https://doi.org/10.22409/1984-0292/v32_i-esp/38850

\section{Copyright:}

Copyright (C) 2020 Tunes, E., \& Prestes, Z. Este é um artigo em acesso aberto distribuído nos termos da Licença Creative Commons Atribuição que permite o uso irrestrito, a distribuição e reprodução em qualquer meio desde que o artigo original seja devidamente citado.

Copyright (C) 2020 Tunes, E., \& Prestes, Z. This is an Open Access article distributed under the terms of the Creative Commons Attribution License, which permits unrestricted use, distribution, and reproduction in any medium, provided the original article is properly cited.

\section{Referências}

ALFANO, Bruno. Deputado do Rio quer testar se professor usa drogas ilícitas a cada três meses. O Globo [online]. 1 out. 2019. Disponível em: https://extra.globo.com/noticias/educacao/ deputado-do-rio-quer-testar-se-professor-usa-drogas-ilicitascada-tres-meses-23986121.html. Acesso em: 24 out. 2019.

ARENDT, Hannah. Entre o passado e o futuro. Tradução de Mauro W. Barbosa. São Paulo: Perspectiva, 2005.

FLUSSER, Vilém. O universo das imagens técnicas: elogio da superficialidade. São Paulo: Anablume, 2008.

FREIRE, Paulo. Conscientização - teoria e prática da libertação: uma introdução ao pensamento do Paulo Freire. São Paulo: Cortez e Moraes, 1979.

HUGO DE SÃO VÍTOR. Didascálicon: da arte de ler. Tradução de Antonio Marchionni. Petrópolis: Vozes, 2001.

ILLICH, Ivan. Celebração da consciência. Tradução de Heloysa de Lima Dantas. Petrópolis: Vozes, 1975.

ILLICH, Ivan. Sociedade sem escolas. Tradução de Lúcia M. Endlich Orth. Petrópolis: Vozes, 1979.

ILLICH, Ivan. Na ilha do alfabeto. In: ILLICH, Ivan et al. Educação e liberdade. Tradução de Nelson Canabarro. São Paulo: Imaginário, 1990. p. 11-35.

ILLICH, Ivan. En el viñedo del texto - Etología de la lectura: um comentario al "Didascalicon" de Hugo de San Víctor. Tradução de Marta I. González Garcia. México: Fondo de Cultura Econômica, 2002.

RANCIÈRE, Jacques. $O$ mestre ignorante: cinco lições sobre a emancipação intelectual. Tradução de Lílian do Valle. Belo Horizonte: Autêntica, 2004.

RISTUM, Marilena. O conceito de violência de professoras do ensino fundamental. 2001. Tese (Doutorado) - Faculdade de Educação da Universidade Federal da Bahia, Salvador, 2001.

RISTUM, Marilena. Violência na escola, da escola e contra a escola. In: ASSIS, Simone Gonçalves de; CONSTANTINO, Patrícia; AVANCI, Joviana Quintes (Org.). Impactos da violência na escola: um diálogo com professores [online]. Rio de Janeiro: Ministério da Educação/ Editora FIOCRUZ, 2010. p. 65-93. Disponível em: http://books.scielo.org/id/szv5t/pdf/ assis-9788575413302-05.pdf. Acesso em: 15 out. 2018.

SECRETARIA DE ESTADO DE EDUCAÇÃO DO DISTRITO FEDERAL. Portaria Conjunta $n^{\circ} 01$, de 31 de janeiro de 2019. Disponível em: http://www.se.df.gov.br/ wp-conteudo/uploads/2019/02/portaria-conjunta-gestaocompartilhada_07fev19.pdf. Acesso em: 12 jun. 2019. 